\title{
THE PRODUCTION OF A LOW DIETARY BULK DENSITY CASSAVA - BASED WEANING FOOD USING FERMENTATION
}

\author{
OSHO S. M. and TAYLOR. O. A. \\ College of Agriculture, Olabisi Onabanjo University, \\ Ago-Iwoye, Ogun State Nigeria
}

\begin{abstract}
Fermentation is an ancient food-processing technique, employed in the preparation of cassava flours for home consumption. This study compares two fermentation procedures practiced at the village level in Nigeria. In the first procedure, sliced cassava chips are soaked in water for 3 days; in the second procedure, the sliced cassava chips are heaped together and covered with straw for 3 days (airfermentation). Cassava flours processed by these two methods were used to make two types of cassava flour porridges, and one type of cassava flour porridge prepared from unfermented cassava. Viscosity measurements were carried out on these porridge. Fermentation by soaking had no marked effect in reducing viscosity and it also produces a whiter flour than flour produced by air fermentation. Viscosity curves, obtained after plotting viscosity against percentage concentration, showed that viscosity is reduced in fermented cassava flours, especially those that are air-fermented, and is reduced still further in cassava flours mixed with legumes. The use of legumes also creates higher nutrient densities in the porridges, but reduced the viscosity of the gruels
\end{abstract}

Key words: cassava, fermentation, weaning foods.

\section{INTRODUCTION}

Cassava Manihot esculenta krantz is an important staple in the diets of millions of Sub-Saharan Africa people. Both the tuberous roots and the leaves are consumed, (IITA, 1996). It is the fourth most important source of food energy in the tropics. More than two-thirds of its total production is used as food for human consumption; the remainder is used for animal feed and for industrial purposes. (Nweke, 1994).

Its importance as an energy source lies in the fact that its roots are rich in carbohydrates. Cassava roots are processed into three main staples in Nigeria, lafun, fufu and gari. The processing involves peeling, soaking, fermentation and retting to make lafun or fufu. The flour obtained is cooked to form a stiff paste, which is consumed with a stew [Hahn, 1989].

Gari is the most popular of the cassava products and the sequential processing takes from one to seven days (Sanni, 1994). When the flour from cassava roots is cooked into gruel [porridge], the starch granules bind large amounts of water resulting in a gruel of high viscosity. If a more liquid consistency is preferred for child feeding, the traditional way to obtain it, is to dilute the gruel with more water, thus decreasing its 
energy and nutrient density. Therefore the child must eat larger portions to satisfy his or her nutrient requirement. This phenomenon of high volume or viscosity in a food is known as "dietary bulk", and its significance in relation to child-feeding practices is serious for populations that depend entirely on starchy staples as the main source of energy for both young children and adults. [Ljungqvist et al, 1981].

According to United Nations protein-calorie advisory group (PAG, 1973) a gruel with a low dry matter content of $10 \%$ will have a low energy density, thus contributing to an inadequate intake of energy. Energy-rich supplements such as fats in the preparation of weaning foods was found to be important (Water low and Payne, 1975; Cameron and Hofvaber, 1976). Energy density was found to be of relative importance and decisive factor when compared to feeding frequency and appetite in regards to the energy needs of preschool children, in several studies conducted by Rutishauser and Freed (1973) and Rutishauser $(1974,1975)$.

According to Handershot (1972) fermentation has a significant effect in reducing the overall dietary bulk of starchy foods apart from the sensory advantages [flavour, color changes, and smell) and improvements that the fermentation process imparts on food.

Many small-scale cassava fermentation processes have been studied and found to impact an increase in protein content by a factor of 6-8. The increase in protein content results either from a conversion of the starch to protein during fermentation or from the mycelia or microbial protein of the organisms involved in the fermentation Okafo (1977). Karlsson and Svanberg (1982) also reported that there was reduction in viscosity as a result of enzymes released during fermentation and during germination of cereals. According to Osho (1994) legumes fortification with soybean, and groundnuts, resulted in end products of high nutritional value especially increased protein which helps in alleviating protein energy malnutrition in growing children. Soybeans contain $40 \%$ protein and about $20 \%$ oil content, while groundnuts contain $25 \%$ protein and $40 \%$ oil content.

The objective of this study was to determine whether the bulk properties of cassava flours constitute a limiting factor in quality of cassava flour gruels.

\section{MATERIALS AND METHODS}

Six samples of cassava flour, obtained from IITA were used, each processed differently. Cassava varieties used were classified into sweet and bitter cultivars. No morphological or other taxonomic characteristics seem to be associated with this classification [Nweke 1994]. However it has been shown that the bitter varieties tend to have higher content of cyanogenic glucosides, while sweet ones usually have lower content [Bokanga, 1992]. The bitter and sweet varieties can also be distinguished by chewing a freshly peeled cassava root like carrot. Sweet varieties usually have sweet taste (organoleptic sense), while the bitter variety have a truly bitter and offensive taste, which often remains after boiling of the roots. (Nweke and Bokanga, 1994).

These samples were processed from both sweet and bitter varieties, distinguished by chewing small pieces of the peeled tuber. The processed samples were identified as follows: 
- Sweet fermented and unfermented flours;

- Bitter fermented and unfermented flours; and

- Mixed (sweet and bitter) fermented and air-fermented flours, and unfermented

("Wet-fermented" indicates fermentation by soaking in water; "air-fermented" indicates fermentation without soaking in water; "unfermented" indicates directs drying of peeled tubers in the sun.)

The cassava tubers were dug from the ground, washed with water to remove the sand, and then peeled. They were then split to remove the midrib and sliced into small pieces (chips). The unfermented tubers were spread on a mat outside for sun drying; those intended for wet-fermentation were soaked in a bucket of water and left for 3 days. The air-fermented tubers were heaped together in the shade, covered with straw, and then left to ferment for 3 days. After fermentation, the soaked tubers were spread on a mat for sun drying, and the soaking water was thrown away. After satisfactory drying, the cassava chips were hammer milled and ground into flour.

Cassava flour gruels studied in this experiment were prepared in the laboratory by mixing a known weight of cassava flour with a known volume of distilled water to make a required concentration: $50 \mathrm{~g}$ of flour, for example, mixed with $450 \mathrm{ml}$ of distilled water, gave a gruel of $10 \%$ dry matter. The mixture was heated in a boiling water bath to a cooking temperature of $95^{\circ} \mathrm{C}$ for $10 \mathrm{~min}$, and then allowed to cool. Gruels of concentrations of $2.5,5.0,7.5$, and $10 \%$ were prepared for viscosity measurements from the unfermented, wet-fermented, and air-fermented flours.

For purposes of comparison, gruels from the same flours mixed with legumes (soybeans and groundnuts) were prepared using the same procedure. Cassava flour was mixed with soybean flour at a ratio of 1:1 and with groundnuts at a ratio of 4:1. The two mixtures were mixed, and homogenized by a Stovall 0mni Mixer 230. From the homogenized mixtures, gruels of the required concentrations were prepared as described above.

The viscosities of all the gruels prepared were measured using a Haake Rotovisco Model RVI with an FK/SVII profiled measuring system and a shear rate of $54 \mathrm{rpm}$. The measuring temperature was kept at $40^{\circ} \mathrm{C}$ to allow comparison of different concentrations (5-10\%). The viscosity behaviour of the gruels were investigated with a Brabender amylographic apparatus with a shear rate of $75 \mathrm{rpm}$ (Hallick and Kelly, 1959).

\section{RESULTS AND DISCUSSION}

Gruels either of unfermented or of wet-fermented flour of both varieties of cassava have about the same viscosity at the same concentration (Table 1). By comparison, the air-fermented flour produced gruels with significantly lower viscosities. Although the measured viscosities of the fermented and unfermented flours do not differ, it seems that the soaking of cassava chips in water (wet- fermentation) for some days 
does not particularly affect the starch structure; it appears that, in this treatment, the cassava starch is still able to bind water molecules in the same way as the unfermented cassava flour starch. The concentration/viscosity curves for the three types of gruels in Table 1 It has been reported that during the wet-fermentation of cassava tubers, there is a decrease in $\mathrm{pH}$, during which the flesh becomes soft (0gunsua, 1980).

Wet-fermentation of cassava tubers therefore has little or no effect on the bulk properties of the flour; rather, it results in a soft, whitish product, preferred by many village people.

On the other hand, air-fermented (moist, solid-fermented) flour showed lower values of viscosity (Table 2), when compared with other flours. This type of fermentation therefore have effect on the bulk properties of the flour. Air-fermentation; always promote the growth of amylase-producing moulds, yeasts, or both.

The viscosity of cassava flour gruels mixed with either soybeans or groundnuts is shown in Fig. 1. A reduction in viscosity is seen when either of the legumes are mixed with unfermented or with fermented cassava flour. Mixing legumes with air-fermented flour results in only a small decrease in viscosity as represented in Fig 1. The reduction observed in fortified cassava flours with legumes (Soybeans and groundnuts) can be explained.

The calculated energy density of cassava flour gruels with or without legumes at consistency of $3000 \mathrm{cP}(1 \mathrm{P}=0.1 \mathrm{~Pa} \mathrm{~s})$ (measured at $\left.40^{\circ} \mathrm{C}\right)$ is shown in Table 2. Gruels of unfermented cassava flour have an energy density of about $0.28 \mathrm{kcal} / \mathrm{g}$; a gruel of airfermented flour has an energy density of $0.34 \mathrm{kcal} / \mathrm{g}$. When mixed with legumes, the energy density of the gruels is increased to be between $0.36-0.41 \mathrm{cal} / \mathrm{g}$. Explained by the higher water- binding capacity of the cassava flour as compared with the groundnut and soybean flour, which has high levels of oil content.

The energy densities of the flours were calculated at a fixed viscosity $(300 \mathrm{cP})$ for unfermented, wet-fermented, and air-fermented flours, together with those mixed with legumes at known proportions (Hendershot, 1972). As shown in Table 2, those flours mixed with legumes had slightly higher energy densities than those flours without fortification even with this increase in the energy density, the mixtures; the energy density is still below that needed to satisfy the energy requirements of preschool children which should be about $1.2 \mathrm{kcal} / \mathrm{g}$.

\section{CONCLUSION}

From these investigations, it is apparent that air-fermentation of cassava roots (and thus of cassava flours) reduces viscosity significantly. Although fermentation by soaking in water has no marked effect in reducing viscosity, the procedure results in a whiter flour than is produced by air-fermentation. When legumes are mixed with cassava flour gruels, the energy density of the latter is significantly increased; this implies that a combination of fermentation and fortification or mixing with legumes would provide an 
optimum increase in nutrient density. It was also observed that fortification reduced the viscosity of such gruels. Among the two cassava varieties studied, the sweet-fermented variety seemed to have a higher water-binding capacity (viscosity) at certain concentrations than did the bitter cassava.

Table 1 Viscosity (cP) of cassava flour gruels at different concentrations.

\begin{tabular}{lcccc}
\hline \hline & \multicolumn{4}{c}{ Concentration (\%) } \\
\cline { 2 - 5 } Type of cassava flour & $\mathbf{2 . 5}$ & $\mathbf{5 . 0}$ & $\mathbf{7 . 5}$ & $\mathbf{1 0 . 0}$ \\
\hline Sweet, unfermented & 245 & 1455 & 3070 & 5580 \\
Sweet, fermented & 325 & 1575 & 3350 & 5290 \\
Bitter,unfermented & 160 & 765 & 2020 & 4445 \\
Bitter,fermented & 240 & 1290 & 2785 & 4875 \\
Mixed, air-fermented & 160 & 725 & 2385 & 3390 \\
\hline
\end{tabular}

Note: $1 \mathrm{P}=0.1 \mathrm{~Pa}$.

Table 2 Energy density in cassava flour gruels at a viscosity of $3000 \mathrm{cP}$ with or without mixing with legumes.

\begin{tabular}{lcc}
\hline \hline \multicolumn{1}{c}{ Type of cassava flour } & $\begin{array}{c}\text { Concentration at } \\
3000 \mathrm{cP}(\mathrm{g})\end{array}$ & $\begin{array}{c}\text { Energy density } \\
(\mathrm{kcal} / \mathrm{g})\end{array}$ \\
\hline Sweet unfermented flour & 7.4 & 0.27 \\
Sweet unfermented flour + groundnuts & 8.88 & 0.37 \\
Sweet unfermented flour + soy beans & 10.2 & 0.37 \\
Sweet fermented flour & 7.0 & 0.25 \\
Sweet fermented flour + groundnuts & 9.4 & 0.38 \\
Sweet fermented flour +soy beans & 10.3 & 0.36 \\
Bitter unfermented flour & 7.85 & 0.29 \\
Bitter fermented flour & 8.55 & 0.32 \\
Mixed air-fermented flour & 9.15 & 0.34 \\
Mixed air-fermented flour + groundnuts & 9.6 & 0.41 \\
Mixed air-fermented flour + soy beans & 10.2 & 0.37 \\
\hline
\end{tabular}

Note: $1 \mathrm{P}=0.1 \mathrm{~Pa}$. 


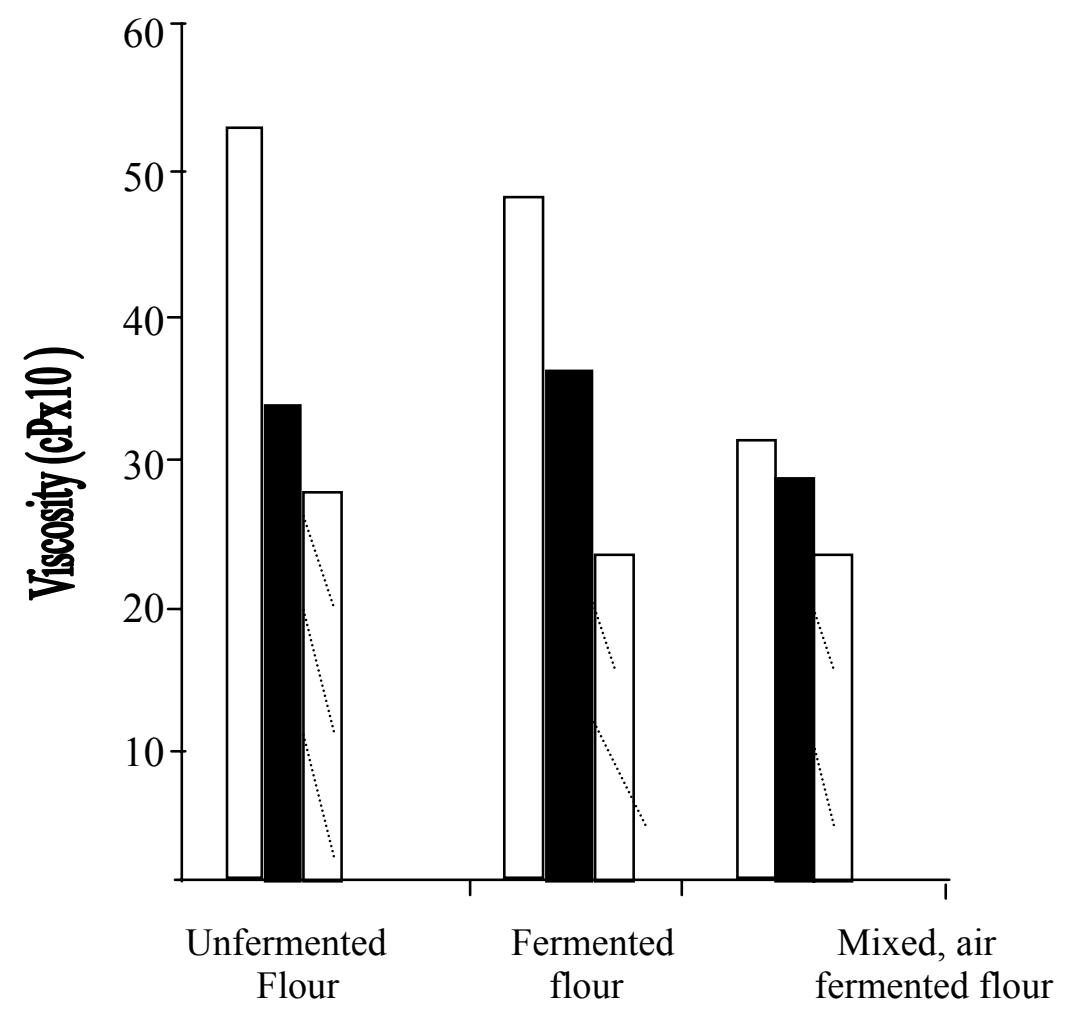

Fig. 1. Viscosities of sweet and mixed cassava porridges at a concentration of $10 \%$, before and after mixing with legumes ( $1 \mathrm{P}=0.1 \mathrm{~Pa} \mathrm{~s})$. $\square$, without legumes; $\boldsymbol{\square}$, mixed groundnuts (4:1); $\not$, mixed with soybean beans (4: 1$)$.

\section{REFERENCES}

Bokanga, M., (1992). Cassava Fermentation and Industrialization of cassava food Production. In: Akoroda, M.O. and 0.3 Arene (eds) Tropical Root Crops:

Promotion of Root Crops Based Industries. Proceedings of the Fourth Triennial symposium of the International Society for Tropical Root Crops-Africa Branch held in Kinshasa 5-8 December 1989. ISTRC-AB, IITA, Ibadan pp. 197-201

Cameron, M., Hofvander, Y. (1976). Manual on feeding infants and young children.

(2nd ed.). United Nations protein-Calorie Advisory Group, New York, NY, USA. Pp 26-34

Hahn, S.K. (1989) "An Overview of African traditional cassava processing and utilization". Out look on Agriculture, 18 (3): 110-118

Hendershot, C.H., (1972). A literature review and research recommendations on cassava. University of Georgia, Athens, GA, USA. Pp 15-21

IITA. (1996). International Institute of Tropical Agriculture Annual Report. IITA. Ibadan, Nigeria. Pp 12-19

Jones, S., Pereira, S.M. (1972). "Calorie intake of pre-school children offered a highcereal diet". Journal of Tropical pediatrics and Environmental Child Health, 18, 196- 198. 
Karlsson, A., Svanberg, U. (1982). "Dietary bulk as a limiting factor for nutrient intake in pre-school children. IV. Effect of digestive enzymes on the viscosity of starch based weaning foods". Journal of Tropical pediatrics, 28 (5), 230-234.

Ljungqvist, B.G., Mellander, O., Svanberg, U. (1981). Dietary bulk as a limiting factor . for nutrient intake in pre-school children. 1. A problem description. Journal of tropical pediatrics, 27, 69.

Nweke F.I and Bokanga (1994) Importance of cassava processing for production in Sub-saharan Africa. Proceeding of International workshop on Cassava SafetyHeld at International Institute of Tropical Agriculture, 1-4 March, Ibadan, Nigeria. $\mathrm{pp}$

Nweke, F.I., (1994) Processing potentials for Cassava production growth. COSCA Working paper No 11. Collaborative study on Cassava in Africa, International Institute of Tropical Agriculture, Ibadan.

Okafor, N. (1977) "Microorganisms associated with cassava fermentation for gari production". Journal of Applied Bacteriology, 42, 279-284.

Osho S.M. (1994). "Emerging food uses of soybean in Africa and Latin America". Paper presented at the world Soybean Conference in Thailand 1994. United Nations Protein-Calorie Advisory Group. (1973) Is there a protein problem? WHO Chronicle, 27, 481-491.

Rutishauser, I.H.E. (1974) "Factors affecting the intake of energy and protein in Ugandan pre-school children". Ecology of Food and Nutrition, 3, 213-222.

Rutishauser, I.H.E., Freed, J.D.L (1973) "The effect of a traditional low-fat diet on energy and protein intake, serum albumin concentration and body-weight in Ugandan pre- school children". British Journal of Nutrition, 29, 261-268.

Sanni, M.O., (1994) "Gari processing in Ibadan metropolis-factors controlling quality at the Small-scale level". Proceedings of the $9^{\text {th }}$ symposium of the International Society for Tropical Root Crops [ISTRC], Accra, Ghana.

Waterlow, J.C., Payne, P.R. (1975). The protein gap Nature (London), 258, 113-117. 